\title{
Pensamentos da Mulher Negra na Diáspora: Escrita do Corpo, Poesia e História ${ }^{1}$.
}

Cristian Souza de Sales ${ }^{2}$

RESUMO: Este artigo tem por objetivo analisar a escrita do corpo feminino negro na produção literária de escritoras afrobrasileiras. Para tanto, foram escolhidas as poesias de Miriam Alves, uma das muitas vozes femininas contemporâneas que tem se empenhado em elaborar outros modelos e novas imagens para o corpo da mulher negra, cujos desenhos, sentidos e significados estão ligados à história e à vivência dos(as) afrodescendentes na diáspora africana. Em seus versos, são inscritas outras formas de dizer este(s) corpo(s) que estão distanciadas das representações estereotipadas, etnocêntricas e falocêntricas construídas, historicamente, por uma tradição cultural no Brasil.

PALAVRAS-CHAVE: escrita feminina negra, poesia, mulheres negras, corpo.

\section{THOUGHTS OF BLACK WOMAN IN DIASPORA: WRITTEN BODY POETRY} AND HISTORY.

ABSTRACT: This article aims to analyze the writing of the black female body in the literary production of Afro-Brazilian writers. To this end, we selected the poems of Miriam Alves, one of many contemporary female voices that have been engaged in developing new models and other images into the body of a black woman, whose designs, meanings are linked to the history and experience of (as) African descent in the African diaspora. In his verses, other forms are entered to say that (s) body (s) that are distant from the stereotypical representations, ethnocentric and phallocentric constructed, historically, a cultural tradition in Brazil.

KEYWORDS: black women's writing, poetry, black women body.

\section{PERCORRENDO A HISTÓRIA, TRAJETÓRIA DO CORPO NEGRO.}

Carregadores

Carregamos nos ombros feito fardos

a luta, a dor dum passado

Carregamos nos ombros feito fardo a vergonha que não é nossa Carregamos nos ombros feito carga

\footnotetext{
${ }^{1}$ As reflexões apresentadas neste artigo foram desenvolvidas durante a elaboração da dissertação de mestrado intitulada Composições e Recomposições: o corpo feminino negro na poesia de Miriam Alves. (SALES, 2011).

${ }^{2}$ Mestre pelo Programa em Estudo de Linguagens- PPGEL, da Universidade do Estado da Bahia- UNEB. Professora da Universidade Aberta do Brasil (UAB/EAD). Email: crissaliessouza@ gmail.com.
} 


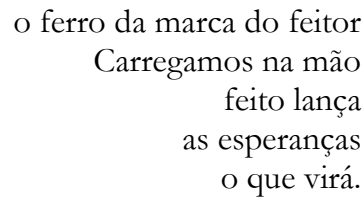
(ALVES, 1985, p.30)

Trazidos para o Brasil na condição de escravos do século XVI até 1850, quando o tráfico foi proibido no século XIX, os povos africanos eram pessoas de "lugares distintos e grupos familiares diferentes" que traziam "diversas interpretações sobre a origem do mundo e formas variadas de se relacionar com os outros", conforme nos apontam Fraga e Albuquerque (2009, p11), em Uma história da Cultura Afrobrasileira. Pessoas que foram retiradas abruptamente de seus lares e que não trouxeram objetos materiais. Nessas condições, transformaram seus corpos no patrimônio mais valioso que tinham, já que neles estavam alojadas muitas histórias, memórias, tradições culturais e religiosas, assim como ritos, mitos, informações identitárias e marcas simbólicas de pertencimento. O corpo era a lembrança do lar, da família, da ligação com os seus ancestrais: da África deixada para trás.

Sem conhecer o vernáculo colonial, apesar da proibição, os africanos, homens e mulheres que foram escravizados(as), usaram seus corpos como elemento de resistência, de comunicação e de interação entre si, o que possibilitou a criação de laços comuns entre povos provenientes de nações, grupos familiares, tribos e etnias distintas. Por meio do movimento, do batuque, da dança e da ginga, dos cânticos religiosos e das músicas entoadas para seus deuses, em inúmeras línguas (Banto, Iorubá, Jeje, Nagô entre outras), foram reconstruídas redes de sociabilidade: "de amizade, de comunidades e de família”. (FRAGA \& ALBUQUERQUE, 2009, p.37).

Dessa forma, os(as) africanos(as) e seus descendentes conseguiram redefinir estratégias de sobrevivência. Contudo, isto não só ancorou a vontade que eles tinham de resistir ao escravismo e "a experiência dolorosa do desenraizamento", assim como alimentou o desejo de lutar por sua liberdade. Funcionou como importante mecanismo de preservação de seus bens simbólicos e imateriais: tradições religiosas e culturais, costumes, histórias, memórias, rituais e contos. (FRAGA \& ALBUQUERQUE, 2009, p.43).

Em Afrografias da memória, Leda Maria Martins (1997, p.24) confirma que os africanos foram transplantados à força para as Américas, através da diáspora africana, e, por essa razão, tiveram seu "corpo e seu corpus desterritorializados". Arrancados de seu domus familiar, esse corpo, individual e coletivo, viu-se "ocupado pelos emblemas e códigos do europeu”, que dele se “apossou como senhor e seu dono", nele "grafando seus códigos linguísticos, filosóficos, religiosos, culturais e a sua visão de mundo". 
Para Martins, os africanos foram "assujeitados pelo perverso e violento sistema escravocrata", tornados "estrangeiros e coisificados". Apesar de tudo isso, "sobreviveram às desumanas condições da travessia marítima transcontinental”. Aqui, foram "destituídos de sua humanidade" e "desvestidos de seus sistemas simbólicos", além de serem "menosprezados pelos ocidentais e reinvestidos por um olhar alheio, o do europeu”. Esse olhar, amparado em uma visão etnocêntrica, depreciativa e eurocêntrica, "desconsiderou a sua história, das civilizações e culturas africanas". (MARTINS, 1997, p.25).

Assim, diferentemente dos sentidos, das crenças e das demarcações pejorativas sobre sua sexualidade e sensualidade, das orientações sugeridas sobre o seu uso, visto como mercadoria e mão- de -obra, corpo-objeto, corpo-produto, representações construídas pelas culturas hegemônicas no Brasil, os corpos negros nas tradições culturais africanas possuíam e possuem outras significações. Nas tradições culturais em África, os corpos têm conotações próprias, ultrapassando as visões negativas e limitadoras, os significados biológicos e mesmos os simbólicos da cultura ocidental. Para os povos africanos, o corpo é importante fonte do saber ancestral: é o lugar de transmissão de conhecimentos, de registro de experiências humanas individuais e coletivas.

Em algumas comunidades, tribos e grupos étnicos na África, marcam-se os corpos e os rostos, "as chamadas escarificações como sinais de pertencimento a um determinado lugar ou grupo familiar”. (FRAGA \& ALBUQUERQUE, 2009, p.14). As escarificações são cortes feitos na pele que ganham formato de desenhos, deixando cicatrizes para realçar a beleza e a coragem em homens e mulheres. Ou ainda elas são feitas para assinalar fases transitórias e específicas na vida das mulheres: a preparação para a fase adulta ou para o matrimônio ${ }^{3}$. Nas tradições culturais africanas, o corpo negro é sinônimo de território, de casa, representa a linhagem identitária do indivíduo. Apresenta-se em sua dupla capacidade de ser e de existir no mundo físico, ao mesmo tempo, como elemento- sujeito da natureza e da cultura.

De modo geral, para as religiões de matrizes africanas, o corpo é considerado como o "veículo de comunicação entre os deuses e forças da natureza", promovendo uma estreita ligação com o Órum (céu) e o Aiê (terra) ${ }^{4}$ É o caminho por onde voduns, inquices, orixás e caboclos se comunicam com o mundo social, unindo o sobrenatural ao mundo físico. Aquele que carrega o Orí (a cabeça física), responsável por sua movimentação, renovação e transformação. É o

\footnotetext{
${ }^{3}$ Em algumas tribos africanas, os desenhos começam a ser feitos nas meninas aos cinco anos de idade. Quando as sequências das imagens feitas no corpo estão completas, elas são consideradas adultas e prontas para o casamento. Ver Dicionário de arte sacra \& técnicas afro-brasileiras, organizado por Raul Lody (2003).

${ }^{4}$ Menciono aqui uma reflexão proposta em $O$ Código do Corpo: inscriçães e marcas dos orixás, por Barros e Teixeira (2000, p-108), sobre a importância do corpo nos rituais de candomblé. Trata-se do artigo publicado no livro Candomblés: religiões do Corpo e da Alma, organizado por Carlos Eugênio Marcones de Moura (2000).
} 
instrumento de interlocução com a espiritualidade, com a ancestralidade, de inserção do sujeito no axé, considerado como a "sede do conhecimento", dos saberes e das intuições 5 .

De acordo com Stuart Hall (2003, p.444), em Da diáspora: identidades e mediações culturais, o corpo negro é um "arquivo de repertórios culturais próprios". Este é o lugar onde se "guardam muitas tradições", bem como as "lutas pela sobrevivência do povo negro na diáspora e, por outro lado, as contranarrativas que lutamos para expressar". Para o autor, as culturas negras na diáspora têm usado o corpo como se ele fosse, e foi muitas vezes, o único "capital cultural" que dispunham e dispõem. E vem, por meio da história, sendo utilizado como um dos "recursos disponíveis" para os(as) afrodescendentes reinscreverem outras narrativas através das informações culturais de seus antepassados, de códigos e de signos, de mitos e ritos herdados. (HALL, 2003, p.342).

Segundo Hall, por essa razão, tivemos que trabalhar em nós mesmos como "telas de representação". E se é no modo como nos "representamos e imaginamos a nós mesmos", é que percebemos "quem somos", aprendemos a valorizar nossas tradições culturais de origem africana, gingados, movimentos, contornos, gestos, modos de vestir, estilos de cabelo, rosto e a cor da pele. Transformamos o nosso corpo negro em um palco de "contestações estratégicas", de lutas e da afirmação estética negra. Nele, produzimos as contraimagens e as contranarrativas que almejamos inscrever: silenciadas, apagadas, ocultadas e "esquecidas" pela historiografia no Brasil. (HALL, 2003, p. 347).

Considerando as ideias de Hall, e sem perder de vista o conjunto de sentidos mencionados sobre o corpo negro, penso que as escritoras afrobrasileiras contemporâneas refletem criticamente sobre as representações depreciativas construídas para o corpo feminino negro, ao longo da história, por uma tradição cultural no Brasil. Em verso ou em prosa, desde o século XVII, os textos literários produzidos no Brasil, em diferentes contextos e momentos históricoculturais, criaram modos de identificação para alteridade, cujo objetivo principal era enquadrar e classificar as mulheres negras, o corpo feminino negro com base em categorias fenotípicas e “escalas cromáticas": a mulata, a negrinha, a pretinha, a moreninha, a crioula, entre outras ${ }^{6}$. Os corpos negros femininos foram inscritos nas relações de gênero estabelecidas pela dominação masculina, sendo submetidos às normatizações sociais, a um conjunto de valores morais e

\footnotetext{
${ }^{5}$ Os termos em Iorubá e seus respectivos significados foram extraídos da Enciclopédia Brasileira da Diáspora Africana organizada por Nei Lopes (2004).

${ }^{6}$ Destaco as terminologias utilizadas por Lídia Avelar Estanislau, em Feminino Plural: negras no Brasil, artigo publicado no livro Brasil Afrobrasileiro, organizado por Maria Nazareth Fonseca (2000). Neste texto, a autora apresenta retratos de mulheres negras que "ultrapassaram as bordas do silêncio", mostrando a efetiva participação da mulher negra na formação da sociedade brasileira".
} 
inúmeras tentativas de controle e disciplina de seus movimentos, de seus gestos e de suas atitudes: de sua aparência e de sua sexualidade?

Cito como exemplo os sonetos atribuídos ao escritor Gregório de Matos dedicados à mulata Jelu; as características da personagem Vidinha, no romance Memórias de um Sargento de Milícias, de Joaquim Manuel de Almeida (1953); as imagens construídas pelo narrador para as personagens afrodescendentes Eufêmia, Esméria e Lucinda, em As Vitimas-Algozes: quadros da escravidão, de Joaquim Manuel de Macedo (1869); os poemas de Castro Alves (1868) nos quais o escritor se refere ao processo de escravização dos negros africanos em nosso país; a representação da personagem Rosa, em A Escrava Isaura, romance escrito por Bernardo Guimarães (1875); a figuração das personagens Rita baiana e Bertoleza, em O Cortiço, de Aluísio Azevedo (1891); O conto intitulado Negrinha, de autoria de Monteiro Lobato (1918); o poema Essa Negra Fulô, de Jorge de Lima (1929), a imagem da mulher negra presente na poesia Irene, de Manuel Bandeira (1930); as personagens afrodescendentes do livro Casa-grande senzala, de Gilberto Freyre (1930); os Poemas da Negra, de Mário de Andrade (1929) e, finalmente, as incontáveis personagens das obras do escritor baiano Jorge Amado, entre elas, destaco o romance Gabriela, cravo e canela (1958), entre outras (os).

Foram e são romances, contos e poemas, cujas representações construídas por alguns autores brancos, em sua maioria, expressam situações em que a malícia, a imoralidade, a permissividade são apresentadas como características inerentes ao comportamento moral da mulher de origem afrodescendente, aparecendo no imaginário brasileiro como um corpo à disposição, pronto para consumo pela dominação masculina branca $^{8}$ : um corpo possuidor de uma sexualidade voraz e pervertida, tratado nas produções literárias mencionadas como um corpo-produto e corpo-objeto.

$\mathrm{Na}$ escrita de cunho feminino negro, que se surge e se fortalece no Brasil em 1978, as autoras utilizam a autorrepresentação como estratégia e recurso de linguagem, de aproximação e de criação de laços comuns com o seu público leitor ${ }^{9}$. Trata-se de um dos mecanismos para elaborar novos sentidos e significações para as mulheres afrodescendentes elaborarem autoimagens positivas. São escritoras que têm buscado questionar e rasurar as representações depreciativas disseminadas sobre o corpo feminino negro.

\footnotetext{
${ }^{7}$ Utilizo o termo "dominação masculina" em consonância com o pensamento de Pierre Bourdieu (1999), em A dominação masculina. Sem mencionar o corpo da mulher negra, mas refletindo sobre as questões de gênero, o autor diz que o corpo feminino se tornou alvo de mecanismos ideológicos. Segundo Bourdieu, a "dóxa masculina" encontrou terreno fértil na articulação mulher, violência e poder, utilizando-se de diferentes estratégias para aplicar "coerções e disciplinamentos" aos seus corpos.

${ }^{8}$ Utilizo o termo "dominação masculina" em consonância com o pensamento de Pierre Bourdieu (1999), em A dominação masculina. Sem mencionar o corpo da mulher negra, mas refletindo sobre as questões de gênero, o autor diz que o corpo feminino se tornou alvo de mecanismos ideológicos. Segundo Bourdieu, a "dóxa masculina" encontrou terreno fértil na articulação mulher, violência e poder, utilizando-se de diferentes estratégias para aplicar "coerções e disciplinamentos" aos seus corpos.

${ }^{9}$ Cito também um coletivo de vozes formadas por Conceição Evaristo, Cristiane Sobral, Celinha (Célia Pereira), Esmeralda Ribeiro, Geni Guimarães, Lia Vieira, Mel Adún, Miriam Alves, Sônia Fátima da Conceição, entre outras.
} 
Nos dizeres poéticos de escritoras como Miriam Alves, as mulheres negras se ocupam em elaborar outras formas de escrita para o corpo feminino negro, à medida que o seu olhar reescreve a história e trajetória das mulheres negras na sociedade brasileira, levando em conta, nessa, outra forma de constituição de corporal negra, as marcações sociais, históricas, estéticas e culturais que este traz consigo. São versos que projetam imagens de um corpo feminino negro carregando as dores do tempo (e de seu tempo), de onde ecoam as vozes de seus/suas antepassados(as) africanos (as), homens e mulheres que vivenciaram as agruras e as amarguras das experiências vivenciadas durante o escravismo colonial e a diáspora africana no Brasil.

Miriam Alves, apropriando-se discursivamente do corpo, a poetisa celebra as mulheres afrodescendentes como sujeitos sexuais autônomos e não como objetos da dominação masculina. A autora imprime uma voz que busca enfatizar a figuração de um “corpo performativo", o qual contradiz os discursos ficcionais brasileiros concernentes à sua posição subalterna e submissa, desvencilhando o corpo feminino negro das marcas de racialização e sexualização impostas pelo racismo e pelo sexismo no Brasil.

\section{MIRIAM ALVES: DESVENCILHANDO O CORPO FEMININO NEGRO DAS} AMARRAS DO SILÊNCIO.

Miriam Alves é autora de um trabalho intelectual em pleno processo de produção até a primeira década do século XXI, formado por um amplo e variado repertório sobre temas e questões ligadas à afrodescendência. Militante do movimento negro, afrofeminista e professora, considerada uma das primeiras mulheres negras a fazer parte do Grupo Quilombhoje Literatura (1982), responsável pela edição e publicação dos Cadernos Negros (1978) até 2012, Alves tem publicado e divulgado seus poemas, contos, ensaios, artigos, no Brasil e no exterior, tendo iniciado a sua carreira nos finais dos anos setenta do século $\mathrm{XX}^{10}$.

Somando mais de trinta anos de carreira, Miriam Alves possui obras literárias traduzidas para o inglês, espanhol e alemão. Em 1982, publicou seus primeiros trabalhos nos Cadernos Negros, lançando no mesmo período duas antologias poéticas: Momentos de Busca (1983) e Estrelas no dedo (1985), consideradas as suas primeiras obras individuais. Coorganizou duas antologias bilíngues (inglês e português): Finnaly Us (Enfim, nós): Contemporary Black Brazilian Women Writers (1991)

\footnotetext{
${ }^{10}$ Os Cadernos Negros têm sido o principal veículo de divulgação de contos e poemas produzidos por autores e autoras afrodescendentes no Brasil até 2012. O último volume foi publicado em dezembro de 2011, contendo apenas contos. São produções ficcionais nas quais os sujeitos da escrita se enunciam como negras(os), constituindo-se como uma nova geração de escritores(as) que se forma a partir de 1970, composta por militantes do Movimento Negro Unificado (MNU), intelectuais, afrofeministas, professores(as), artistas e pesquisadoras(es). Esmeralda Ribeiro e Márcio Barbosa são os atuais organizadores dos Cadernos. As mais recentes publicações da autora podem ser conferidas no volume 34, Cadernos Negros: contos afrobrasileiros, lançado em 17 de dezembro de 2011, com o conto intitulado O velório. Miriam Alves só esteve ausente de nove edições dos Cadernos.
} 
com a professora norte-americana Carolyn Durham e Women righting: afrobrazilian Women's shorts fiction (2005) em parceria com a professora Maria Helena Lima (coletânea de contos). Em edições mais recentes, lançou o livro Brasilafro autorrevelado: literatura brasileira contemporânea (2010), contendo artigos que, em sua maioria, refletem sobre a escrita da mulher negra, e a coletânea de contos Mulher Matri(z): Prosas de Miriam Alves, publicada em 2011.

Marcando o seu lugar de enunciação como sujeito e objeto de sua produção literária, evidenciando a sua identidade racial e de gênero, Miriam Alves constitui uma nova forma de escrita literária, a afrobrasileira, delineando imagens de um corpo negro que se revestem de outros significados e sentidos positivos. São configurações poéticas, cujo sujeito enunciador feminino negro busca estabelecer ligações de um corpo com as suas marcas identitárias, práticas religiosas e culturais de origem afro, superando um conflitivo processo de construção e desenvolvimento de sua autoestima. E a poetisa o faz, em princípio, estabelecendo um diálogo com a sua história ancestral, conforme pode ser lido na poesia:

Mahin amanhã

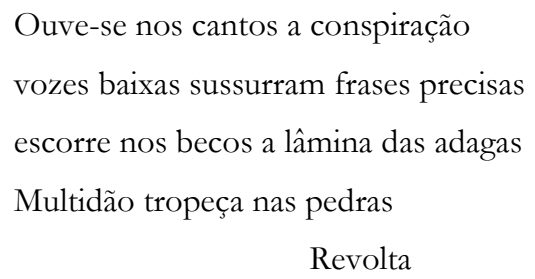




\section{nagôs \\ "é aminhã, Luiza Mahin, falô".}

$\left(\right.$ ALVES, CN, 1986) ${ }^{11}$

Em Mahin amanhã, Miriam Alves recupera a atmosfera de revoltas e rebeliões lideradas por negros escravizados(as) contra a opressão colonial branca no Brasil. Ao revisitar esse passado histórico, o sujeito poético feminino negro contesta a versão oficial, marcando em seu discurso a participação efetiva de uma mulher afrodescendente contra o sistema escravista na luta por sua liberdade, mas, sobretudo, contribuindo para a construção da história do país, através da figura heroica e lendária de Luiza Mahin. Considerada mãe do poeta negro Luís Gama (1828-1861), Mahin teria vivido no século XIX e ficou conhecida por liderar a Revolta dos Malês, movimento antiescravista ocorrido em Salvador, em 25 de Janeiro de 1835, formado por negros livres e cativos pertencentes a diferentes grupos etnicorraciais, referendados no texto pela voz literária: "malês, bantus, geges e nagôs"12.

Os versos descrevem os momentos que antecederam a rebelião que foi liderada por Luiza Mahin. Reencenam a resistência africana e feminina, "tramada na língua dos orixás", além de efetivar rasuras no modo como a imagem da mulher afrodescendente foi edificada pela visão masculina colonial e pela historiografia brasileira durante séculos sob os "signos da submissão e da passividade”, estando ela escravizada ou livre. Forte, guerreira, líder de rebeliões, articuladora e participante de movimentos pela libertação dos(as) escravizados(as), protagonista de sua história de vida, - são essas as modelações escolhidas pela voz literária no ato de (re)esculpir a representação da mulher negra na contemporaneidade.

Por meio da história de Mahin, ainda aberta a investigações, revisitadas pelo olhar feminino negro, a memória coletiva invisibilizada, negada e apagada pelo registro da história, conhecida como oficial, emergem informações sobre os nossos antepassados africanos. A partir dela, o sujeito literário reitera a importância da presença da mulher na formação da história dos povos afrodescendentes no Brasil. Chamo de memória coletiva aquela que Jacques Le Goff (1990, p.366) define, em História e Memória, como a responsável pela "conservação de informações", relacionada a práticas culturais, aos saberes e à transmissão de experiências: seja de forma oral ou por escrito, preservada e difundida, neste caso, pelas vozes femininas afrodescendentes ${ }^{13}$. Uma memória colocada em "jogo" de forma importante na "luta das forças

\footnotetext{
${ }^{11}$ Texto selecionado nos Cadernos Negros: melhores poemas (1998).

${ }^{12} \mathrm{Na}$ década de trinta do século XX, Pedro Calmon escreveu o romance Malês - A insurreição das senzalas, o qual traz Luiza Mahin como personagem principal.

${ }^{13} \mathrm{~A}$ oralidade é característica fundamental na tradição das sociedades africanas. Os textos são regravados pela memória do grupo e a eles pertencem uma atitude radicalmente oposta à que ocorre na criação literária. $\mathrm{O}$ que vale é repassar a transmissão do saber através de gerações pela tradição oral, depositária do conhecimento empírico das experiências materiais e espirituais vivenciadas pelo grupo, com o qual o narrador tem uma interatividade constante. (CASTRO, 2008, p.14).
} 
sociais pelo poder", manipulada pelos "senhores do esquecimento e da lembrança" com intenção de "controlar o passado e o presente de sociedades históricas". (LE GOFF, 1990, p.368).

Segundo Yeda Pessoa de Castro (2008, p.13), em As Vožes do Saber, as civilizações "negroafricanas" não conheceram o apoio do letrismo como um dos artifícios importantes no processo de "transmissão de ideias e aquisição da sabedoria". No Brasil colonial, essa "tradição oral rnilenar" foi amplamente difundida pelas vozes das mulheres negras na condição de "mães-pretas, mucamas, velhas contadoras de estórias e pelas sacerdotisas negro-africanas", líderes de movimetos antiescravistas, narradoras dos "feitos heróicos dos seus deuses, reinos e ancestrais", mecanismo que aliviava os sofrimentos e castigos gerados pelo processo de escravização a que estavam submetidos(as).

Da oralidade aos tempos da escrita, sob o ponto de vista simbólico, a produção ficcional da mulher negra na primeira década do século XXI refaz os laços que reaproximam gerações distintas. Ao relacionar memória e história, o passado e o presente se comunicam a partir de um encontro forjado pela voz poética feminina, colaborando para a formação de uma linhagem identitária etnicorracial e de gênero, constituída por outras gerações de mulheres afrodescendentes. Das velhas para as mais novas, o estilo de resistência, de luta e de combate deixado pela heroína (Luiza Mahin) vai sendo reconfigurado de acordo com o contexto histórico e as situações de opressão vivenciadas por elas. Herança preservada e retransmitida por um "rosário rezado conta a conta", composto por fios que sustentam e vão, tempo a tempo, estabelecendo outras representações sociais ${ }^{14}$ :

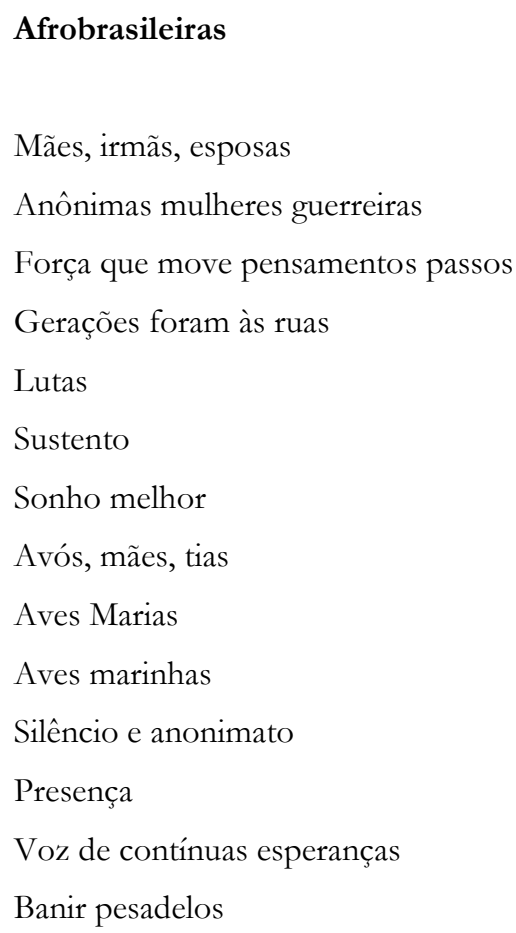

${ }^{14}$ Retiro trechos do poema do Passo, Praça, publicado por Miriam Alves, nos Cadernos Negros, número 17, em 1995. 
Da vida do país.

(ALVES, CN, 2008, p.99).

Por meio dessa linhagem, a voz feminina negra apresenta outros papeis sociais desempenhados pelas afrobrasileiras que estão referidas nos versos exercendo as funções de "mães e esposas", relações de parentesco quase sempre ausentes nas imagens disseminadas pela literatura brasileira. É o que igualmente corrobora o olhar da escritora e poetisa afrobrasileira Conceição Evaristo (2005, p-53) no ensaio intitulado Da representação a autorepresentação da mulher negra na literatura brasileira sobre as personagens afrodescendentes construídas pelos textos literários nacionais de autoria masculina:

[...] uma leitura mais profunda da literatura brasileira, em suas diversas épocas e gêneros, nos revela uma imagem deturpada da mulher negra. Um aspecto a observar é a ausência de representação da mulher negra como mãe, matriz de uma família negra, perfil delineado para as mulheres brancas em geral. Mata-se no discurso literário a prole da mulher negra. [...] na ficção, quase sempre, as mulheres negras surgem como infecundas e perigosas. [...] desgarradas da família e distante do casamento. (EVARISTO, 2005, pp.53-54, grifos meus).

A família sempre significou para as mulheres afrodescendentes um modelo de "sobrevivência e forma de resistência contra as desigualdades raciais". No retrato construído pelo sujeito literário feminino negro, na poesia Afrobrasileiras, são quatro as fotografias e gerações que aparecem mencionadas: a avó, a mãe, a tia e a irmã. A partir de um "solo comum", iniciado das mais velhas para as mais novas (as filhas), segundo Ecléa Bosi (1994, p.423), em Memória e sociedade: lembranças de velhos, as recordações de um "grupo doméstico" persistem e vão sendo "matizadas" em cada um de seus membros, de forma "una e diferenciada", contudo, guardam "vínculos difíceis de separar e de ser apagados totalmente". E é por meio desses "vínculos" que os sentimentos de origem de um grupo ficam "enraizados"; vínculos retransmitidos por mães reais ou "simbólicas" - presentes nas irmandades - nas confrarias ou nas "Casas de axé", segundo Evaristo - zeladoras de muitos segredos, muitas histórias, zeladoras de muitas cabeças, "heroínas" de nosso cotidiano.

Mulheres negras que foram e são responsáveis pela preservação da memória cultural de seu grupo, pelo próprio sustento e subsistência de suas famílias. "Guerreiras anônimas" que vivenciam e compartilham experiências semelhantes de discriminação ligadas ao sexismo e ao racismo, os quais sempre atuaram juntos sobre elas.

Das reivindicações feitas no próprio lar junto aos seus companheiros - à conscientização política sobre o seu lugar étnico e de gênero desenvolvida em contato com a militância feminina negra - no interior dos movimentos sociais e nas associações de mulheres - exigindo políticas públicas de reparação na luta contra o racismo e o sexismo, as afrobrasileiras (avós, mães, tias e esposas) denunciam formas de discriminação e de preconceito que as tornaram principal alvo em 
todos os níveis: o econômico, o estético, o religioso, o cultural, o educacional, o profissional e nas relações afetivas, entre outros(as).

“Anônimas mulheres", longe de qualquer clamor por glórias, cujas falas tornaram visíveis às realidades específicas das afrobrasileiras no tocante às desigualdades de gênero, de classe e de raça, que se anteciparam às contribuições e aos estudos teóricos sistematizados pela crítica feminista nos Estados Unidos e desenvolvidos no Brasil somente a partir de $1980^{15}$. Triplamente discriminadas, por serem negras, mulheres e pobres, em grande parte, moradoras de regiões periféricas, elas "pressionaram" o feminismo tradicional a repensar a sua pauta de reivindicações, exigindo o cruzamento dos termos "gênero, raça e classe" como forma de produzir aproximações, mas, sobretudo, diferenças entre as próprias mulheres ${ }^{16}$.

É o que fica evidente no discurso de Miriam Alves (2010, p.66), dessa vez fora do campo literário, no ensaio Mulheres negras: vozes na literatura, no qual a autora reflete sobre o momento em que essas reclamações mais ou menos foram iniciadas:

[...] a partir das décadas de 1960 e 1970, escritoras e as mulheres negras engajadas com as questões do feminismo, mas também com a discriminação racial, realizaram debates dentro e fora do Movimento Negro, levantando novas questões sobre o papel das afrodescendentes no contexto da sociedade brasileira, dando visibilidade às inquietações relegadas ao silêncio. (ALVES, 2010, p.67, grifos meus).

Esse silêncio mencionado por Miriam Alves no fragmento pode ser traduzido por vidas marcadas e "eivadas de relações": de amores, desamores, sabores, dissabores, dores, ódios, esperanças, desesperanças, sonhos, medos, desejos, "risos e choros", conquistas e reconquistas as quais são (re)elaboradas "nos textos literários poético-ficcionais" sob a perspectiva das escritoras afrobrasileiras. São vozes, discursos e olhares femininos que imprimem a sua identidade de gênero e etnicorracial por meio de outras imagens e novos desenhos que ancoram modos diferenciados de viver, de ser e de "estar no mundo" para as mulheres negras. (ALVES, 2010, p.184). Afirma que o nosso corpo traz uma história e uma tradição cultural que não podem ser esquecidas:

Pedaços de mulher

$[\cdots]$

Mulher - retalhos

a carne das costas secando

\footnotetext{
${ }^{15}$ Tomo como referência as reflexões pioneiras sobre gênero e raça promovidas por Lélia Gonzalez (1983) intitulada Racismo e Sexismo na cultura brasileira. Além disso, me apoio nos trabalhos da crítica feminista realizadas no Brasil por Sandra Azeredo (1994) e Sueli Carneiro (1994) e no exterior por bell hooks (1996), Lily Caldwell (2000). Feministas e afrofeministas que articulam em suas reflexões a relação entre gênero, raça e classe.

${ }^{16}$ Em Institucionalização dos estudos sobre a mulher negra: perspectivas do Brasil e dos Estados Unidos, Lily Kia Caldwell (2010) examina o campo de estudos feministas no Brasil e nos Estados Unidos entre 1970 e 1980. Nele, a autora cita nomes de importantes intelectuais negras brasileiras no tocante à militância e à produção intelectual na construção do pensamento e da teoria do feminismo negro no Brasil: Lélia Gonzalez, Beatriz Nascimento, Sueli Carneiro, Thereza Santos, Edna Roland, Luiza Bairros e Fátima Oliveira.
} 


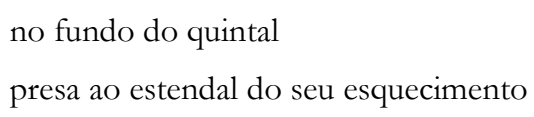

\section{Mulher - revolta}

agito-me contra os prendedores

que seguram-me firme neste varal

\section{Eu mulher \\ arranco a viseira da dor enganosa.}

(ALVES, 1985, p.45, grifos meus).

$\mathrm{Na}$ tessitura do poema, o sujeito literário feminino faz uso de um recurso estilístico denominado por Leda Maria Martins (2007, p.71), em A Fina Lâmina da palavra, "retórica de retalhos", uma "técnica de composição", na qual "os objetos inseridos, as situações descritas, as figuras e os temas evocados" são compilados a partir de "restos e resíduos do cotidiano" ou são trazidos rastros de acontecimentos históricos. Além disso, são utilizados elementos linguísticos e semânticos que darão formato às representações pretendidas: a "mulher-retalhos, a mulherrevolta e o eu mulher”. Essas figurações podem ser lidas como se fossem as três expressões dos “eus" corpo da mulher negra ${ }^{17}$.

Construindo outra explicação sobre a presença de um corpo retalhado na escrita feminina de um modo geral, mas, sem considerar nesta relação o cruzamento raça e gênero, Lúcia Castello Branco (1991, p.147), em um Fio de voz tecendo o vazio, afirma que o "corpo em retalhos", certamente, significa "imergir na fragmentação do discurso" feminino, onde "as palavras se querem coisas, mas não passam, irremediavelmente, de palavras”. Para a autora, trata-se de um discurso que opta por uma fala crítica constituída de "meias-palavras, de meias-verdades e de meias-revelações”. Penso que Miriam Alves produz um discurso literário crítico, contudo, sem as “meias-palavras, sem meias-verdades ou as meias-revelações”. É o que posso observar nas três representações femininas que surgem na poesia Pedaços de Mulher.

$\mathrm{Na}$ primeira estrofe, a mulher-retalhos relembra as práticas de violência vivenciadas por suas ancestrais africanas no passado colonial: "a carne das costas secando". O seu olhar poético retoma as dores dos cortes feitos na pele negra, revive simbolicamente os episódios de castigos físicos impostos aos corpos negros escravizados, reabrindo as feridas deixadas pelo regime colonial. Submetidos a formas coercitivas de disciplina e de controle, os "signos de pertencimento e de identidade, as escarificações e as tatuagens", trazidos com os/as africanos(as), aos poucos, foram sendo substituídos pelo "sinal de posse impresso a ferro e a fogo ou pelos

\footnotetext{
${ }^{17}$ É interessante observar que parte dessa estrutura é montada com ajuda dos hífens: é como se unidas, as palavras
} representassem uma coisa só: mulher, retalhos e revolta. 
adereços perversos" colocados em seus corpos: "algemas, colares de ferro e coleiras". (FONSECA, 2000, p.97) ${ }^{18}$.

$\mathrm{Na}$ segunda estrofe, a mulher-revolta, agitando-se contra seus "prendedores", traz à cena as dores que ficaram registradas no corpo e na memória dos afrodescendentes, assim como as aspirações transmitidas pela mulher-retalhos. É na fala, na voz, nas ações, nos versos e nos movimentos que ela dá forma a um corpo-mulher-negra guerreiro e insurgente, o qual se ergue contra os "esquecimentos" produzidos pela historiografia no Brasil, concernentes às formas de violência praticadas pela dominação patriarcal. Um corpo em enunciação que se impõe ao seu silenciamento, ao seu apagamento e ao seu aprisionamento, reescrevendo a "história social e cultural" das mulheres negras. Um corpo negro que se "insubordina contra o "lugar-comum da repetição estereotípica" quanto à sua fragilidade e passividade. (MARTINS, 2007, p.70) ${ }^{19}$.

Nas linhas finais da poesia, "eu mulher" representa não apenas um "eu”, mas um coletivo de mulheres negras que a antecedeu. "Pontilhada nas frestas e nos retalhos de uma escritura" literária, a qual se nutre de episódios históricos, de lutas e de reações anteriores, ela torna possível o desejo de libertar o corpo feminino negro das dores e das "amarras" do silêncio, curando as feridas deixadas pelo passado escravo. (MARTINS, 2007, p.70). Ao desenraizar sofrimentos e amarguras, o en mulher negra igualmente confronta as tiranias e as opressões estabelecidas historicamente sobre si.

Na poesia em questão, estabelecendo novas representações sociais para o corpo feminino negro, Miriam Alves menciona mais uma vez em seu discurso literário as feridas não cicatrizadas pelo tempo - as marcas históricas - simbólicas - sociais e culturais que este carrega. A escritora reúne esses vários "pedaços de mulher" e promove uma mudança em seu modelo de autorrepresentação. A transformação na perspectiva e no posicionamento aponta para a questão da visibilidade da mulher negra enquanto sujeito que passa se definir na escrita ficcional de Miriam Alves.

Adotando um modo de autoafirmação que o ser mulher negra lhe confere na atualidade e marcando o seu lugar de enunciação, o "eu mulher" apresenta-se por um lado consciente em suas identidades feminina e etnicorracial e, por outro, assumido e defendido com orgulho e vivacidade. Assim, constrói modos próprios de representação, deixando de ser objeto de figuração na escrita do outro para se tornar, ao mesmo tempo, sujeito, personagem e objeto de sua produção literária.

\footnotetext{
${ }^{18}$ Cito mais uma vez o artigo Visibilidade e Ocultação da diferença: imagens de negro na literatura brasileira, escrito por Maria Nazareth Fonseca.

${ }^{19}$ Penso que a palavra quintal empregada por Miriam Alves alude aos lugares sociais destinados às mulheres afrodescendentes historicamente. Lugares subalternos: os fundos da casa, onde em algumas residências localizam-se as cozinhas. Mais uma vez, a poetisa remete-nos a imagem de um corpo feminino negro tratado como objeto para ser explorado como força de trabalho, entretanto, esta representação é rejeitada por ela.
} 
O sujeito mulher negra "retira o véu", "descobre-se" e desvela-se. Mediante a palavras e versos, toca "o próprio corpo", trazendo à cena a voz e o rosto (re)interpretados em emoções e subjetividades próprias para "registrar e se autorrepresentar no território da literatura afrobrasileira", procurando dar "visibilidade a corpos-vida" que são redesenhados nas "falas da existência". Assim, enfoca os mais diferentes aspectos e situações, expondo e desnudando as “complexidades que revestem" o ser mulher negra na sociedade brasileira. (ALVES, 2010, pp.185186).

Entoando uma "contra-voz", o sujeito mulher negra segue opondo-se aos estereótipos vários sobre o seu corpo. "Toma o lugar da fala e da escrita, assim como se toma o direito e o lugar da vida”, evocando a inspiração poética para constituir o seu corpo feminino negro de representações outras. (EVARISTO, 2005, p.54). E, dessa forma, este vai tecendo a trama para a construção de uma "manta longa de entrelaçamentos e significados", combinando ritmos, timbres, sons, marcas identitárias e culturais, imagens e mensagens, conforme é possível identificar nos versos a seguir:

No espelho sou o olhar

o olhar que me percorre formas

e pela fresta sou eu

espiando-me inquieta

$[\cdots]$

O coração em ritmo tambor

decifra mensagens

as palavras voam ao vento

Vão

E a cada tan tan do coração

novas frases se formam

Vão

ao vento

o meu ser luma

no seu contumaz leve brilho

Vai

luzindo emoções indecifráveis

(ALVES, CN, 2008, p.149, grifos meus).

No poema em destaque, o sujeito mulher negra se reconhece na figura refletida no espelho; espelho que traduz o discurso criativo de Miriam Alves, no qual a escritora tanto tece uma nova forma de desenho para o corpo feminino negro, assim como, tomando como base o reflexo das palavras e dos versos, passa a significar e a ampliar expectativas, sonhos e desejos. Contemplando a sua imagem, as formas e os contornos do corpo 
feminino negro são apreciados em sua especificidade e diferença: rosto, nariz, olhos, a cor da pele, textura do cabelo. Os traços étnicos que desprestigiados e menosprezados, motivavam o complexo de inferioridade, passam a ser valorizados e admirados, revestidos de autoestima e de dignidade. A pele, o rosto e a beleza feminina negra brilham - o seu "leve brilho contumaz". Beleza feminina negra irradiada pelo brilho da lua, alude a voz poética feminina.

Criando um efeito sonoro, as aliterações em / v/ dão ritmo e musicalidade aos novos modos de dizer o corpo feminino negro, promovendo as repetições necessárias que vão embalando e despertando novas emoções e sentimentos no eu lírico, além de produzirem mensagens novas que amplificam seus sons nos versos e, ao toque do tambor e do atabaque, fazem pulsar o coração da mulher negra. O tambor nas tradições culturais africanas é revestido de muitas significações e possui variados formatos de sons e funções. "O som que emite, se usado ritualisticamente, é portador de energia vital de axé”. (LOPES, 2004, p.639) ${ }^{20}$. Trata-se do "instrumento africano mais importante" para o culto, para a confraternização, para a dança ou para o lazer, utilizado como ferramenta de comunicação para contar histórias de povos, de etnias e de seus antepassados, transmitir notícias, enviar e receber mensagens ancestrais, bem como para ligar o corpo às suas práticas religiosas e/ou espiritualidade. (FRAGA \& ALBUQUERQUE, 2009, p.97).

No período colonial, “o som dos tambores e o requebro dos corpos negros" eram vistos como "coisas diabólicas", por isso, não eram "permitidos nem mesmo nas senzalas". Entretanto, "não faltava quem se arriscasse, deixando-se levar pelo som das palmas", dos cânticos, das músicas, dos tantãs e dos batuques: no samba, na capoeira e no candomblé. (FRAGA \& ALBUQUERQUE, 2009, p.100). Traços culturais de origem africana que sempre foram bastante desprestigiados pela tradição ocidental.

Contudo, em lugar de tentar negá-los ou mesmo substituí-los por outros, a voz poética feminina, na atualidade, encarrega-se de fortalecer esses laços identitários e simbólicos. Miriam Alves faz questão de destacar que a melodia e o som que regem a beleza dos movimentos do corpo das mulheres negras, oferecendo-lhe sentido, voz, harmonia, compasso aos gestos, expressão e linguagem, possuem ligação com a história de seus antepassados. Por isso, ancorada por essa linhagem afroidentitária, a autora segue revestindo

\footnotetext{
${ }^{20}$ Florentina Souza investigando a poesia de autores e autoras afrodescendentes vai dizer que a imagem dos tambores é utilizada por vários poetas e poetisas, funcionando como dispositivo simbólico de incentivo à afirmação étnica e de grande significado simbólico para os universos culturais africanos e da diáspora. (SOUZA, 2005, p.189). Por outro lado, a autora afirma que os tambores criam e estabelecem elos firmes entre o corpo, o som, a voz, o ritmo com o seu tocador. "É pelo seu toque mais agressivo ou mais carinhoso que o instrumento marcará o tempo ou compasso com maior ou menor intensidade", produzindo diferentes significados. (SOUZA, 2007, p.257).
} 
o corpo feminino negro de "falares feiticeiros" que estabelecem uma mítica conexão com "a energia vital, a força do axé e as cores dos orixás", guiada pela Iris do arco-íris:

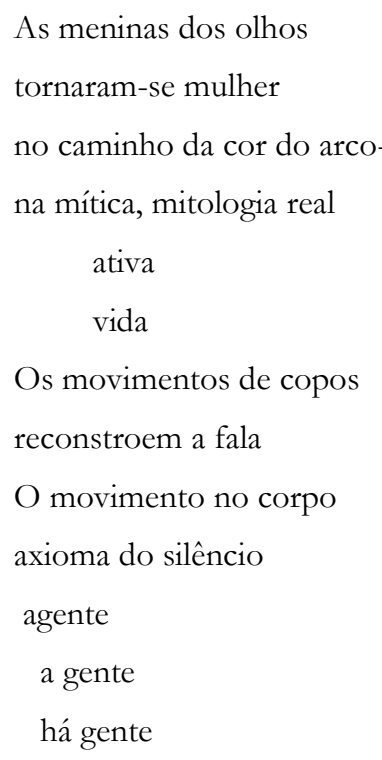

\section{Ah! Gente}

Há

avanço na expressão

os corpos falam

(ALVES, 2002, p.30) ${ }^{21}$

Retoma-se na poesia a importância das mitologias africanas na compreensão de simbologias relacionadas aos corpos negros. Em suas múltiplas cores, o arco-íris para além das explicações dos fenômenos naturais ligados à Física, tem para os povos africanos e os adeptos do candomblé outras representações. O arco-íris é o símbolo do orixá Oxumarê, o qual é responsável pela "movimentação e pela renovação da vida"22. Trata-se de uma entidade do candomblé ligada à terra e à natureza. Por meio dessa invocação sagrada, da dança-ritual, de seus dons, da incorporação nos versos de palavras magnetizadas no mundo sobrenatural e invisível, a vOz poética alude para a transição e para as mudanças coletivas realizadas pela mulheres negras no mundo social quanto à sua autoimagem.

Da menina à mulher, do silêncio à fala, do antes ao agora, o sujeito poético mostra as etapas de uma luta calcada no passado para reestabelecer ao corpo feminino negro, no presente, expressões, movimentos e outras possibilidades de interpretação. Implicitamente, são mencionadas vozes de mulheres negras que desafiaram a dor, o choro, a submissão, a revolta, a invisibilidade social e as formas discriminatórias de representação de seu corpo em outros tempos. Mulheres negras "agentes", atentas, persistentes, com poderes e dons, cheias de

\footnotetext{
${ }^{21}$ Título do poema publicado pela autora nos Cadernos Negros em 2002, volume 25.

${ }^{22}$ No candomblé, orixá é simboliza pela cobra (Dan). Oxumarê é uma palavra de origem Nagô. Ver Enciclopédia Brasileira da Diáspora Africana, p.130.
} 
esperança, que fizeram parte de gerações distintas, cuja referência é mencionada nas linhas do texto através da palavra: "a gente” (nós) 23.

O verbo "haver" empregado duas vezes (há), embora apresente significados diferentes, ambos sintetizam o resultado das conquistas obtidas pelas mulheres negras brasileiras na atualidade. Enfatizam as vozes do corpo-mulher em diálogo e em liberdade: o alcance da visibilidade social e da liberdade de expressão. O uso da interjeição acompanhado do sinal exclamativo (ah!) expressam essas mudanças, gerando a sensação de alívio no eu lírico. Assim, ultrapassando barreiras históricas, inaugura-se um ciclo novo, no qual são realizadas antigas reivindicações e feitas outras exigências. Mas, sobretudo, abre-se um novo espaço, no qual se constroem outra tradição literária, uma nova forma de escrita deste corpo mulher negra que se apresenta como possibilidade concreta.

Nas poesias analisadas, referindo-se à história da África e dos seus antepassados africanos, ao passado colonial, à resistência nos quilombos, "as revoltas escravas", às tradições religiosas de origem africana, aos "acontecimentos históricos, elementos e eventos simbólicos", os textos literários das mulheres negras tentam representar as suas "investidas individuais e coletivas para se inserirem, de modo suplementar, na sociedade brasileira". (SOUZA, 2005, p193). Para Florentina Souza, em Afrodescendência em Cadernos Negros e Jornal MNU (2005, p. 196), as escritoras afrobrasileiras produzem "contraimagens" que são compostas e propostas a partir do "resgate do passado, dos traços desqualificados para elaboração de outras identidades: sem contorno fixo, múltipla, relacional ou móvel”, mas que "descentrará as imagens desenhadas pelos estereótipos inferiorizantes".

Segundo Souza, Miriam Alves e outras poetisas negras constituem "imagens alternativas e diferenciadas sobre o corpo feminino negro, geradas no interior de um processo de convivência, muitas vezes, tensa e "problemática", com "a cultura ocidental hegemônica". Por isso, são mulheres que lutam para "expressar-se" com rosto, voz, corpo, tinta e papel, deixando impressas as suas digitais, acrescentando ao universo patriarcal, hegemônico e branco um estilo literário outro, agora o feminino negro. Seguem no manuseio da/com a palavra, do fio (linguagem) e do tecido (poesia), "tecendo e desenhando" de um modo especial, seus corpos negros, entrelaçados a muitas "histórias, memórias e identidades". Uma produção literária afrobrasileira que sugere caminhos de ação e insubordinação contra o racismo e o sexismo, mas que também aborda o afeto, o amor, a sexualidade, com "beleza", encanto e "sedução". (SOUZA, 2005, pp.196-197).

Penso que, nas poesias de Miriam, as tessituras elaboradas para o corpo feminino negro revelam uma das etapas de uma luta calcada no passado para reestabelecer a este corpo, no

\footnotetext{
${ }^{23}$ A expressão coloquial “a gente” é usado para se referir ao pronome pessoal do caso reto (nós).
} 
presente, expressões, movimentos e outras possibilidades de interpretação. Implicitamente, a escritora afrobrasileira menciona vozes de mulheres negras que desafiaram a dor, o choro, a submissão, a revolta, a invisibilidade social e as formas discriminatórias de representação de seu corpo, disseminadas em outros tempos e em outros modos de expressão cultural no Brasil. Remete-nos às mulheres negras "agentes", atentas, persistentes, com poderes e dons, cheias de esperança, que fizeram parte de gerações distintas e que jamais desistiram de lutar contra as formas de discriminação a que estiveram submetidas. São linhas poéticas que enfatizam as vozes do corpo-mulher negra, rompendo, em definitivo, as amarras do racismo.

\section{REFERÊNCIAS}

ALVES, Miriam. Momentos de Busca. São Paulo: Do Autor, 1983.

ALVES, Miriam. Estrelas de Dedo. São Paulo: Do Autor, 1985.

ALVES, Miriam. Pedaços de mulher. Entrevista. In: MARTINS, Leda Maria; DURHAM, Carolyn; PERES, Phylis; HOWELL, C. (Ed.). Callaloo, v. 18, n. 4, African Brazilian Literature, an special issue. Baltimore: John Hopkins University Press, 1995.

ALVES, Miriam. BrasilAfro autorevelado: literatura afrobrasileira contemporânea. Belo Horizonte: Nandayla, 2010.

ALVES, Miriam. A literatura negra feminina no Brasil-pensando a existência. Revista ABPN, v. 1, n. 3 - nov. 2010 - fev. 2011, p. 181-189.

BARROS, José Flavio Pessoa de. e TEIXEIRA, Maria Lina Leão. O Código do Corpo: inscrições e marcas dos orixás. In: Candomblé: religião do corpo e da alma, tipos psicológicos das religiões afrobrasileiras. (Org) Carlos Eugênio Marcondes de Moura. Rio de Janeiro: Pallas, 2000.

BRANDÃO, Ruth Silviano e BRANCO, Lúcia Castello. A mulher escrita. Rio de Janeiro: Casa Maria Editorial, 1989.

BRANCO, Castello Lúcia. As incuráveis feridas da natureza feminina. In: A mulher escrita. Rio de Janeiro: Casa Maria Editorial, 1989.

BRANCO, Castello Lúcia. Um fio de voz tecendo o vazio. In: BRANCO, L. C., BRANDÃO, R. S. (Orgs.). A mulher escrita. Rio de Janeiro: Casa-Maria Editorial, 1989, p.87-109.

BOURDIEU, Pierre. A dominação masculina. Trad. Maria Helena Kühner. Rio de Janeiro: Bertrand Brasil, 1999.

CADERNOS NEGROS 25. São Paulo: Quilombhoje Literatura, 2002.

CADERNOS NEGROS 31. São Paulo: Quilombhoje Literatura, 2008.

CASTRO, Yeda Pessoa de. As Vozes do Saber. Revista do Instituto Geográfico e Histórico da Bahia. Salvador, v. 103, p. 13-24, 2008. 
FRAGA, Walter Fraga. Uma bistória da Cultura Afrobrasileira/Wlamyra R. de. Albuquerque. São Paulo: Moderna, 2009.

FONSECA, Maria Nazareth. Visibilidade e ocultação da diferença: imagens de negros na cultura brasileira. In: FONSECA, Maria Nazareth Soares (org.). Brasil afro-brasileiro. Belo Horizonte: Autêntica, 2000, p.87-116.

HALL, Stuart. Da diáspora: identidades e mediações culturais. Liv Sovik (org). Belo Horizonte: UFMG; Brasília: Representação da UNESCO no Brasil, 2003.

HALL, Stuart. A identidade Cultural na pós-modernidade. São Paulo: Fundação Memorial da América Latina, 1997.

LODY, Raul. Dicionário de arte sacra \& técnicas afro-brasileiras. Rio de Janeiro: Palhas, 2006.

LOPES, Nei. Enciclopédia da Diáspora Africana. São Paulo: Selo Negro: 2004.

MARTINS, Leda. A fina lâmina da palavra: o negro na literatura brasileira. In: MUNANGA, Kabengele (Org.). História do Negro no Brasil. O negro na sociedade brasileira: Resistência, participação, contribuição. Brasília: Fundação Palmares-MinC, 2004.

MARTINS, Leda. O feminino corpo da negrura. Revista de Estudos de Literatura. Belo Horizonte, v. 4, p. 111 -121, Out, 1996.

MARTINS, Leda Maria. Afrografias da memória. São Paulo: Perspectiva, Belo Horizonte: Mazza Edições, 1997.

SALES, Cristian Souza de. Composições e recomposições: o corpo feminino negro na poesia de Miram Alves. (Dissertação de mestrado). Salvador: UNEB, 2011.

SOUZA, Florentina da Silva. Afrodescendência em Cadernos Negros e Jornal MNU. Belo Horizonte: Autêntica, 2005.

SOUZA, Florentina da Silva. Vozes Femininas do Atlântico negro. In. Marcas da Diferença: as literaturas africanas de língua portuguesa. Org. Rita Chaves e Tânia Macedo. São Paulo: Alameda, 2006. 
SOUZA, Florentina da Silva. Laços poéticos forjados pelo Atlântico negro. In: Brasil África: como se o mar fosse mentira. Rita Chaves, Carmem Secco e Tânia Macedo (Orgs). São Paulo: Unesp, Luanda, Angola, 2006, p. 249-241 